\title{
Body condition changes arising from natural factors and fishing gear entanglements in North Atlantic right whales Eubalaena glacialis
}

\author{
Heather M. Pettis*, Rosalind M. Rolland, Philip K. Hamilton, Amy R. Knowlton, \\ Elizabeth A. Burgess, Scott D. Kraus
}

Anderson Cabot Center for Ocean Life at the New England Aquarium, Central Wharf, Boston, MA, USA

\begin{abstract}
Body condition has been correlated with survival and reproductive success in both terrestrial and marine mammals, including North Atlantic right whales Eubalaena glacialis. We used photographs of individually identified right whales to assess visual changes in body condition in reproductive females, adult males, juveniles, and entangled whales. Images from sightings of individual whales were grouped sequentially by habitat region, and each group of images was assigned a body condition score of good, fair, or poor based on the dorsal profile posterior to the blowholes. Temporally consecutive groups of images $(n=1496)$ of 340 individual whales were compared to investigate the frequency, direction, and minimum timeframe between changes in body condition. Changes in body condition scores of right whales were significantly influenced by group category. Lactating females and severely entangled right whales were more likely to exhibit declining body condition than other groups. Resting females were significantly more likely to improve in condition than other groups but exhibited the longest timeframe for improving condition. Young juveniles were less likely to improve in condition compared to adult males, but remained in compromised condition less frequently than older juveniles and adult males. The shortest timeframes between changing body condition scores were $11 \mathrm{~d}$ for declining condition and $12 \mathrm{~d}$ for improving condition. This study demonstrates that photographic analysis can detect rapid body condition changes and identifies groups of right whales that are particularly vulnerable to declining condition and delayed recovery from energetically taxing events.
\end{abstract}

KEY WORDS: Right whale $\cdot$ Entanglement $\cdot$ Body condition $\cdot$ Anthropogenic injury $\cdot$ Marine mammal

\section{INTRODUCTION}

The North Atlantic right whale Eubalaena glacialis remains one of the most endangered large whales in the world, despite a myriad of agency and institutional recovery efforts (van der Hoop et al. 2013). High levels of anthropogenic-related mortality as well as variable annual reproductive rates in E. glacialis have led to population growth that is lower $(\sim 2.6 \%)$ than their southern right whale E. australis counterparts $(\sim 7.5 \%)$ and other large baleen whale species in the western North Atlantic (Best et al. 2001, Kraus et al.

${ }^{*}$ Corresponding author: hpettis@neaq.org
2007, Waring et al. 2015). In recent years, research efforts have focused on understanding the mechanisms behind suppressed reproduction and low population growth rates of North Atlantic right whales, including assessments of the role that individual health may play (Reeves et al. 2001, Pettis et al. 2004, Rolland et al. 2007a, 2016, Doucette et al. 2012, Fortune et al. 2013, Schick et al. 2013).

Body condition, a metric used to estimate relative energetic reserves, has been correlated with survival and reproductive success of both terrestrial (Young 1976, Schulte-Hostedde et al. 2001) and marine mam-

(C) The authors 2017. Open Access under Creative Commons by Attribution Licence. Use, distribution and reproduction are unrestricted. Authors and original publication must be credited. 
mals (Lockyer 1986, 1993, Pitcher et al. 1998, Hall et al. 2001, Pettis et al. 2004, Rolland et al. 2007b, 2016, Miller et al. 2011) and is often used to assess and monitor the overall health of animal populations (Beck et al. 1993, Gerhart et al. 1996, Pitcher et al. 1998, Bradford et al. 2012, Williams et al. 2013). In large whale species, energetic reserves are stored in, and mobilized from, the blubber layer, visceral tissues, and muscles (Lockyer et al. 1985, Aguilar \& Borrell 1990, Niæss et al. 1998), and thus characteristics of these tissues, including thickness and chemical composition, are considered to be primary indicators of overall body condition (Lockyer et al. 1985, Miller et al. 2011). Standard means of assessing the body condition of marine mammals, including live capture or direct post mortem measurements (Lockyer et al. 1985, Beck et al. 1993, Nilssen et al. 2001, Koopman et al. 2002, Wells et al. 2004) are inappropriate for tracking individual and population-wide health in rare, free-ranging large whale species. The development and application of several new methods, such as ultrasonic measurement of blubber thickness (Moore et al. 2001, Angell 2005, Miller et al. 2011), vertical aerial photogrammetric measurements of length and width (Perryman \& Lynn 2002) and visual assessments of body contours (Pettis et al. 2004, Bradford et al. 2012) have allowed researchers to document correlations between changes in body condition and periods of known energetic stress and recovery in large whale species, including right whales (Perryman \& Lynn 2002, Pettis et al. 2004, Rolland et al. 2007b, Miller et al. 2011, 2012, Bradford et al. 2012).

The right whale visual health assessment method (Pettis et al. 2004) uses photographs to assess the overall health of individual whales by evaluating several visible parameters, including relative body condition. Although it provides a more subjective and semi-quantitative measurement than methods such as direct ultrasonic blubber thickness measurements or photogrammetric measurements, the use of images routinely taken for photo-identification provides a much larger data set and allows for retrospective analyses. The broad scope of these data allows for monitoring of both short and long-term changes in condition and assessment of the impact these changes have on individual whale health and population dynamics. For example, previous analyses have suggested correlations between poor body condition and decreased survival and reproduction in right whales (Pettis et al. 2004, Rolland et al. 2007b).

Although it is clear that significant loss of body condition greatly reduces survival probability for right whales (Pettis et al. 2004), the amount of time that it takes to detect changes in body condition has not been described and likely varies demographically. Energetic demands on individual right whales are not uniform across the population and can be influenced by both natural and anthropogenic processes. The high energetic costs of reproduction have been well documented for large whales (Lockyer 1986, Perryman \& Lynn 2002), including right whales (Miller et al. 2011, Fortune et al. 2013), and previous visual health assessment analyses have documented decreases in body condition during lactation, as well as increases in condition just prior to pregnancy (Pettis et al. 2004). Age-length curves for known-age right whales derived from necropsy and photogrammetric measurements indicate that rapid growth occurs from 0 to $4 \mathrm{yr}$, with the most dramatic growth occurring in the first 12 mo after birth (Moore et al. 2004, Fortune et al. 2012), suggesting an elevated energetic demand for this demographic group. Additionally, ultrasonic measurements showed increased blubber thickness in older juveniles (8 yr) compared to younger juveniles (1 to 2 yr) (Miller et al. 2011). Anthropogenic impacts, including entanglement in fishing gear, may impede foraging ability, increase energy draw due to disruption of the hydrostatic oral seal (Lambertsen et al. 2005, Cassoff et al. 2011), or increase drag forces created by the entangling gear (Knowlton \& Kraus 2001, Cassoff et al. 2011, van der Hoop et al. 2014). Although each of these factors creates energetic demands, the degree to which they alter body condition as well as the speed at which changes can be visually detected have not been characterized.

The purpose of this study was to examine and compare timeframes of changes in visual body condition for right whales with varied energetic demands due to natural and anthropogenic factors. In addition to determining the sensitivity of the visual health assessment method to detect changes in body condition, understanding the minimum timeframe of visually detected changes in right whale body condition has important implications for management and research efforts. Establishing characteristics of body condition changes for various demographic segments of the population will provide essential information to managers who are assessing potential consequences of anthropogenic disturbance (i.e. entanglement and vessel strikes) and inform prognoses for injured whales. And, in the case of entanglements, understanding how quickly body condition can change may allow for more accurate estimates of windows of opportunity for successful intervention. 


\section{MATERIALS AND METHODS}

\section{Identification and visual health assessment databases}

Data for this study were obtained from the North Atlantic Right Whale Identification Database (hereafter 'Identification Database') and Visual Health Assessment Databases (Right Whale Consortium 2011). Individual North Atlantic right whales are identifiable by unique patterns of raised epithelial tissue (callosities) on their head region, as well as scars and other body markings (Payne et al. 1983, Kraus et al. 1986), and they have been intensely studied for the past 30+ yr (Hamilton et al. 2007, Kraus \& Rolland 2007). Sightings of right whales throughout their geographic range, from both dedicated survey and opportunistic efforts, are incorporated in the Identification Database that contains information on sighting history, age, sex, behaviors, and associated data for all photographed right whale sightings.

The visual health assessment method developed for right whales is based on evaluation of 4 physical parameters including body and skin condition, presence and severity of rake marks around the blowholes, and accumulation of orange cyamids in and around the blowholes (see Pettis et al. 2004 for details). As the purpose of this study was to investigate characteristics of body condition changes in right whales, only the body condition parameter was analyzed, based on observations from 1980 to 2011. The collection of visual health data follows the methodology developed for evaluating scars on right whales (Knowlton et al. 2012, Schick et al. 2013, Rolland et al. 2016). Photographs from all sightings of an individual whale were grouped sequentially by right whale habitat region (e.g. Great South Channel, Gulf of Maine, Cape Cod Bay, Bay of Fundy) (Right Whale Consortium 2011, Waring et al. 2015) and those groups of images were referred to as 'sighting batches'. Each time a whale moved to a new region, or was not sighted for more than 1 mo in a given region, a new sighting batch was created. The only exception to this grouping procedure is that sightings of a whale in adjacent regions within a month of each other were combined into 1 batch. These sighting batches can represent a single sighting or dozens of sightings of a whale spanning $1 \mathrm{~d}$ to $5 \mathrm{mo}$. All images in each batch were evaluated together and a single body condition score was assigned. Because the quality of the images varied from sighting to sighting, and only one side of a whale was photographed in some sightings, the body condition score repre- sents a composite of information gleaned from all the sightings in the batch. Though uncommon, some body condition scores changed within a batch. Currently, 25 batches $(0.15 \%)$ in the Visual Health Assessment Database have changes in scored body condition within a batch. For those cases, the final body condition score for the batch was entered into the database and the batch was marked as 'changing' so that timeframes between changing conditions could be calculated. Body condition scores and associated batch information, including date range of batch, sighting region, and comments related to condition, were incorporated into the Visual Health Assessment Database. The Identification and Visual Health Assessment databases are linked so that spatial, behavioral, and life history data can be coupled with health data.

\section{Body condition data and study groups}

The body condition parameter uses visible body contours to estimate the relative amount of subcutaneous fat in a right whale. The body condition parameter is scored on a 3-point scale of good, fair, and poor. Whales scored as 'good' had a flat or slightly convex dorsal profile posterior to the blowholes when viewed laterally, whales scored as 'fair' had a slight to moderate concavity, and whales scored as 'poor' were characterized by marked concavity dorsally and/or laterally (see Pettis et al. 2004 for representative images of scores). In addition to assessing the dorsal profile, the position of the whale's head relative to its back was considered, as head lifts and arched backs can distort the body contours (Pettis et al. 2004). Additionally, not all batches of right whale sightings could be scored for body condition. Assessing this parameter requires images of the whale's dorsal profile viewed from the side, therefore sightings collected from aerial platforms or photographs that did not include a lateral view could not typically be scored.

Here, we analyzed all consecutive sighting batches of images of individual right whales where both batches were scored for body condition. For each consecutive batch pair (herein referred to as an 'observation'), the change in body condition and the timeframe in days between the consecutive batches (calculated as the end date of the first batch to the start date of second batch) were calculated. If more than 2 consecutive batches were scored for body condition for an individual whale, the start date of a batch served as the end point for one comparison, and the end date for that same batch served as the 
start for the next comparison. Data for this study included sightings throughout the geographic range of right whales and were restricted to consecutive batches separated by $365 \mathrm{~d}$ or less in order to reduce the potential for missed body condition changes between temporally distant batches, as well as to restrict inter-batch timeframes to a single annual migration, feeding, and reproductive cycle.

To determine timeframes of body condition changes related to both natural and anthropogenic energetic demands, the following study groups were identified:

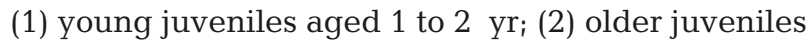
aged 3 to $8 \mathrm{yr}_{\text {; }}$ (3) adult males (known-age male whales aged $\geq 9$ yr or unknown-age male whales with a sighting history of $\geq 9 \mathrm{yr}$ ), (4) lactating females (reproductive females transitioning from pregnancy [first batch] to lactation [second batch]); (5) resting females (reproductive females transitioning from lactation [first batch] to a recovery year [second batch]); and (6) entangled whales with attached fixed fishing gear (in the first and/or second batch), with entanglement injuries categorized by level of severity as minor, moderate, and severe (see Knowlton et al. 2016). The age of the whale at the later batch was used to place the individual into the appropriate category. Juveniles were separated into 2 categories to account for foraging inexperience and thus greater nutritional challenge in recently weaned 1 to $2 \mathrm{yr}$ old juveniles (Miller et al. 2011, Fortune et al. 2013). Calves were not included as they are still nursing until about 12 mo of age (Hamilton et al. 1995, Hamilton \& Cooper 2010) and thus are not expected to be nutritionally challenged. The classes of reproductive females were selected based on the energetic demands at different stages in the calving cycle (Miller et al. 2011, 2012, Fortune et al. 2013). Adult males were included as a population reference group as their energetic requirements are expected to be stable relative to other demographic groups (Fortune et al. 2013).

\section{Statistical analyses}

To investigate temporal aspects of body condition changes in relation to demographics, the timeframes between consecutive batches for individual whales were computed, and the number of body condition declines, improvements, and no changes were tallied for all observations within each study group. Timeframes were calculated as the number of days from the end of one batch to the start of the following batch for those whales that did not change condition within a batch series. For those whales that did exhibit changes in body condition within a single batch of sightings, each sighting was examined to determine the timeframe of change that occurred within the batch. Timeframe data were presented as mean number of days \pm SEM.

Sighting heterogeneity of right whales has been well documented (Brown et al. 2001) and presented challenges for comparing the timeframe of changing body condition. In order to describe the variation in recorded timeframes between batches across study groups and to interpret the data accordingly, we used a linear mixed model with a normal error structure. In the full factorial model, group category and change in body condition score were included as fixed effects, and individual whale identity fitted as a random term.

To analyze changes in the body condition of whales, we used a generalized linear model with a multinomial (ordinal) probability distribution and cumulative logit as the link function. A full factorial model was used to examine the effects of potential predictor variables (i.e. group category, body condition score, timeframe, individual whale) on observed change in body condition score (response variable) in all whales. This analysis was followed by a multinomial logistic regression to identify how a whale's reproductive state and entanglement severity influences a change in body condition, using adult males as the reference group.

Chi-square $\left(\chi^{2}\right)$ analysis was used to compare frequencies of observed individuals with improved (score change $=1$; no whales were recorded improving by 2 body condition scores), declined (score changes -2 and -1 were combined) or unchanged (score change $=0$ ) body condition across all groups. For those whales repeatedly sampled within a group and body condition score, one observation was included to ensure individuals were represented only once in these statistical analyses.

For those whales exhibiting body condition changes (i.e. improving or declining), we compared number of days between consecutive batches according to nonentangled groups using 1-way ANOVA; comparisons of improved or declined body condition over time across entangled whale groups could not be conducted due to inadequate sample sizes in these groups.

Transition times between body condition states of good, fair, and poor were investigated for each study group and described using minimum values. All analyses performed were considered significant at $\mathrm{p}<$ 0.05 . Assumptions were met by visually checking residual distributions and Q-Q plots. Post hoc Bonferroni tests of pairwise multiple comparisons were 
used to identify all significant differences. Data were analyzed using SPSS statistical software version 20.0 for Macintosh (IBM).

\section{RESULTS}

\section{Consecutively scored sighting batches}

Of 10786 sighting batches scored for visual health from 1980 to 2011, 2014 batches scored for body condition representing 1496 batch pairs were included in this study. These 1496 observations were associated with 340 unique individuals. Adult males had the largest number of observations of body condition ( $\mathrm{n}=604$ ), whereas whales with minor, moderate and severe entanglements had the fewest $(n=8,19$, and 28 , respectively).

Timeframes recorded between consecutive batches scored for body condition ranged from 3 and up to $365 \mathrm{~d}$ (mean $\pm \mathrm{SE}, 214.0 \pm 3.0 \mathrm{~d}$ ). Timeframes varied significantly across study groups $\left(F_{7,369}=2.92, \mathrm{p}=\right.$ 0.006) but were not influenced by the individual whale $\left(F_{338,18}=0.95, \mathrm{p}=0.60\right)$ or change in body condition score $\left(F_{2,243}=0.17, \mathrm{p}=0.85\right)$. Results showed that overall longer timeframes were recorded for resting females $(251.6 \pm 12.1 \mathrm{~d})$ and minor entanglement cases $(317.9 \pm 11.4 \mathrm{~d})$, and shorter timeframes for moderate entanglement cases $(151.1 \pm 28.2 \mathrm{~d})$, severe entanglement cases $(163 \pm 22.0 \mathrm{~d})$ and lactating females $(170.4 \pm 13.5 \mathrm{~d})(\mathrm{p}<0.05)$. Adult males $(220.5 \pm 4.8 \mathrm{~d})$, older juveniles $3-8$ yr $(214.8 \pm 5.2 \mathrm{~d})$ and younger juveniles $1-2$ yr $(205.1 \pm 6.5 \mathrm{~d})$ had intermediate timeframes for consecutively scored batches ( $\mathrm{p}<0.05)$ (Fig. 1).

\section{Characteristics of body condition changes}

Changes in body condition scores of right whales were significantly influenced by group category (Wald statistic $=27.81, \mathrm{df}=7, \mathrm{p}<0.001$ ), but were not related to recorded timeline between batches (Wald statistic $=1.36, \mathrm{df}=1, \mathrm{p}=0.24)$, body condition score (Wald statistic $=0.006, \mathrm{df}=2, \mathrm{p}=1.00$ ) or individual whale identity (Wald statistic $=75.76, \mathrm{df}=336, \mathrm{p}=$ 1.00). Lactating females $(b=2.68$, Wald statistic $=$ 61.17, $\mathrm{p}<0.001$, where $b$ is the unstandardized beta regression coefficient) and severely entangled whales $(b=1.49$, Wald statistic $=11.66, \mathrm{p}=0.001)$ were more likely to decline in condition. Resting reproductive state in females $(b=1.29$, Wald statistic $=13.59, \mathrm{p}<$ 0.001) was a significant predictor of improving body

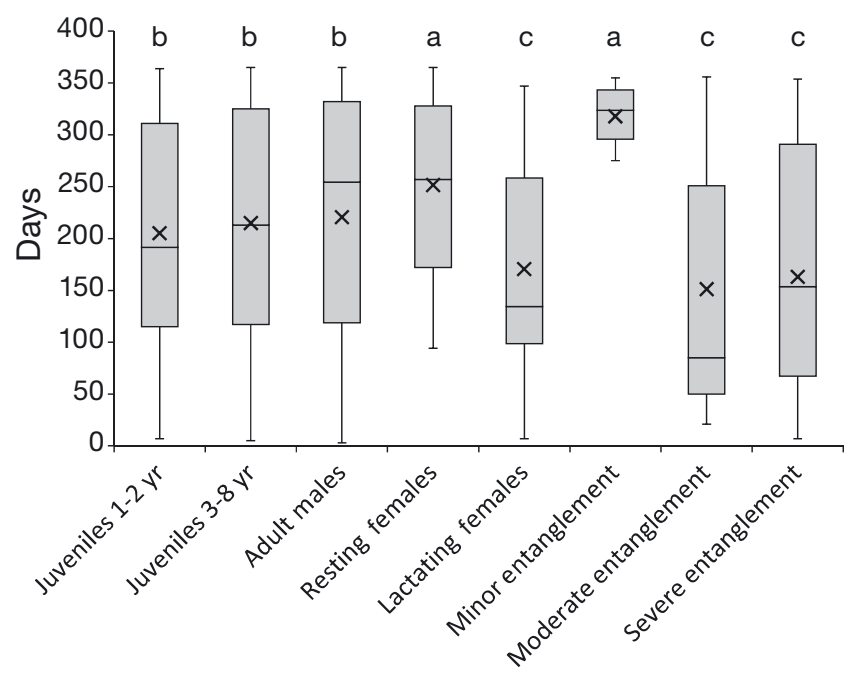

Fig. 1. Comparison of timeframes (number of days) between sighting batches consecutively scored for visual body condition in North Atlantic right whales. Study groups without entanglement included: juvenile $1-2$ yr $(n=270)$, juvenile $3-8$ yr $(n=477)$, adult male $(n=604)$, resting female $(n=46)$ and lactating female $(\mathrm{n}=44)$. Entangled individuals were classified into groups with minor $(\mathrm{n}=8)$, moderate $(\mathrm{n}=19)$, and severe $(\mathrm{n}=28)$ entanglement. In the boxplots, the line inside the box indicates the median value, ' $x$ ' represents the mean value, the height of the box encompasses the distance between the $25^{\text {th }}$ and $75^{\text {th }}$ quartiles, and the whiskers delineate extreme observations (minimum and maximum). Different letters above the boxes denote significant differences in timeframes between study groups in Bonferroni post hoc tests at $\mathrm{p}<0.05$

condition. Juveniles 1-2 yr $(b=-1.07$, Wald statistic $=$ 9.37, $\mathrm{p}=0.002)$ and $3-8 \mathrm{yr}(b=-0.63$, Wald statistic $=$ 7.13, p = 0.008) juveniles were significantly less likely to have improving body conditions. Neither minor nor moderate entanglement category was predictive of declining $(p=0.995$ and $p=0.531$, respectively) or improving ( $p=0.919$ and $p=0.974$, respectively) conditions.

The incidence of improving, no change (i.e. stable) or declining changes in body condition in right whales was significantly associated with demographic and entanglement categories $\left(\chi^{2}=106.95\right.$, df $=14, p<$ $0.001)$. Of the whales exhibiting a decline in body condition $(18.0 \%, \mathrm{n}=120)$, lactating females $(62.5 \%$, $\mathrm{n}=25$ ) were more likely to decline in condition than other groups $(\mathrm{p}<0.05)$ (Table 1). Juvenile 1-2 yr whales $(78.5 \%, \mathrm{n}=135)$, followed by juveniles $3-8 \mathrm{yr}$ $(74.2 \%, \mathrm{n}=138)$, were more likely to maintain a stable body condition (either good or fair) compared to other group categories, $(\mathrm{p}<0.05)$. Among whales with improving body condition, adult males $(24.1 \%$, $\mathrm{n}=46)$ and resting females $(31.0 \%, \mathrm{n}=13)$ were the most prevalent $(\mathrm{p}<0.05)$, whereas no females during 
Table 1. Incidence and percentage, by group category, of type of change in visual body condition observed between consecutive batch pairs of North Atlantic right whales. For batch pairs for which body condition remained unchanged, the incidence and percentage of those remaining in good, fair, and poor condition are reported. Incidence of improving, declining and no change in body condition was significantly associated with demographic and entanglement categories $\left(\chi^{2}=\right.$ 106.95, $\mathrm{df}=14, \mathrm{p}<0.001$ ) as was the incidence of remaining in good, fair, or poor condition $\left(\chi^{2}=112.95, \mathrm{df}=14, \mathrm{p}<0.001\right)$. Each superscript letter denotes a subset of group categories whose column proportions do not differ significantly from each other $(p<0.05)$

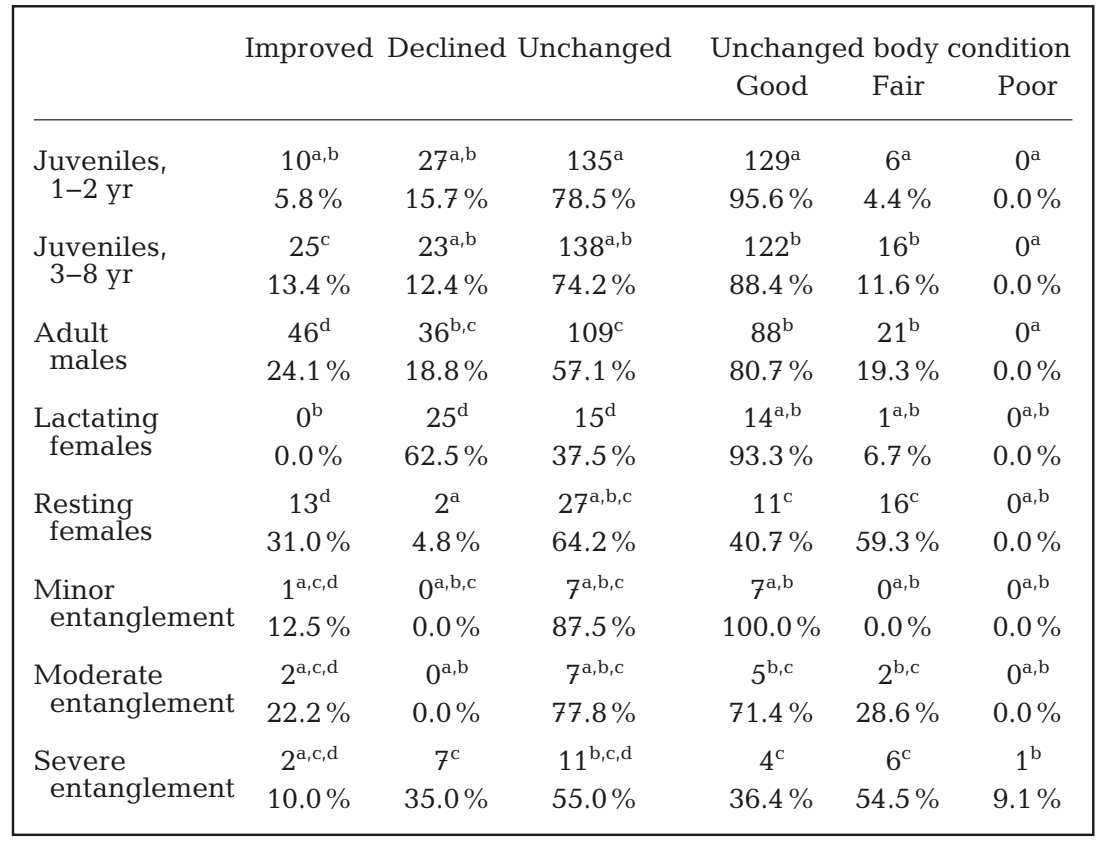

lactation exhibited an improvement in body condition (Table 1). Juveniles 1-2 yr were less likely to improve in condition compared to both adult males and juveniles $3-8 \mathrm{yr}(\mathrm{p}<0.05)$.

Right whales exhibiting no change in body condition between consecutive batches were represented across all groups. The incidence of remaining at good, fair, or poor condition was significantly related to group category $\left(\chi^{2}=112.95, \mathrm{df}=14, \mathrm{p}<0.001\right)$. Resting females $(59.3 \%, \mathrm{n}=16)$, severely entangled right whales $(63.6 \%, \mathrm{n}=7)$ and moderate entanglement $(28.6 \%$, $\mathrm{n}=2$ ) had a significantly higher proportion of individuals remaining in a compromised condition (i.e. fair or poor body condition) than all other group categories (Table 1). Severe entanglement was the only group of whales with poor condition recorded in consecutive batches (Table 1). Juveniles 1-2 yr were less likely to remain in compromised (fair) condition than juveniles 3-8 yr and adult males. Maintaining better body condition was significantly more common among juveniles 1-2 yr $(95.6 \%, \mathrm{n}=129)$ than among all other groups and right whales with minor entanglements $(100 \%, \mathrm{n}=7)$ (Table 1$)$.
Timeframes for improving body condition varied significantly among study groups $\left(F_{3,110}=4.65, \mathrm{p}=\right.$ 0.004) (Fig. 2). Right whales with the longest timeframes for recovering body condition were resting females $(281.5 \pm 19.0 \mathrm{~d})$, with intermediate timeframes exhibited for juveniles $3-8 \mathrm{yr}(231.3 \pm 20.0 \mathrm{~d})$ and the shortest timeframes for improvements in body condition for juveniles $1-2$ yr $(151.9 \pm 25.9 \mathrm{~d})$ and adult males $(195.6 \pm 12.6 \mathrm{~d})$. Lactating females did not show improved body condition between batches and were not included in the analysis. Declines in body condition were detected over shorter timeframes for lactating females $(158.9 \pm 14.3 \mathrm{~d})$ than for adult males $(240.2 \pm 11.8 \mathrm{~d})$, which exhibited the longest timeframe for decline in body condition $\left(F_{4,152}=3.94, \mathrm{p}=\right.$ 0.005). Juveniles of all ages $(1-2 \mathrm{yr}=$ $192.3 \pm 17.0 \mathrm{~d} ; 3-8 \mathrm{yr}=219.9 \pm$ $18.2 \mathrm{~d})$ and resting females $(238.5 \pm$ 90.5 d) exhibited no significant difference in timeframe of body condition decline (Fig. 3).

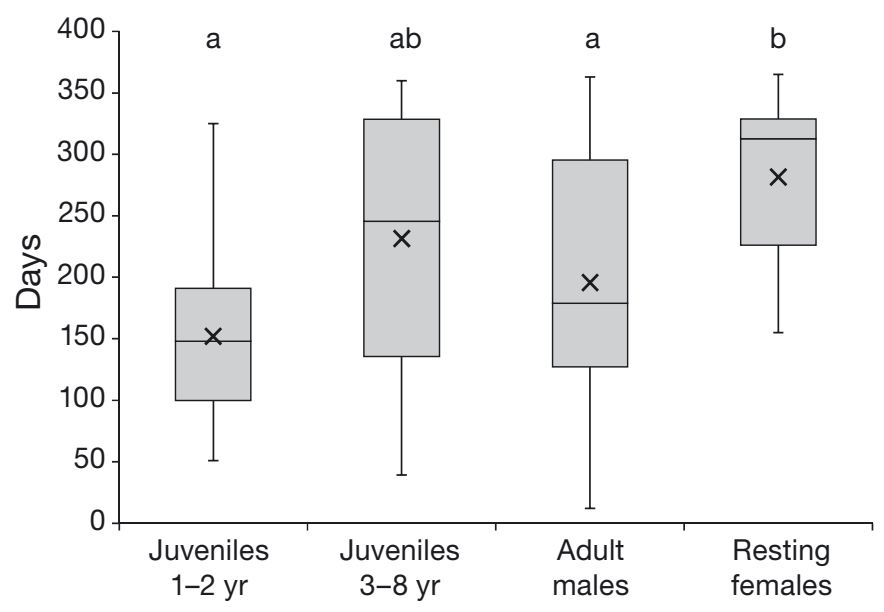

Fig. 2. Comparison of timeframes (number of days) for improving body condition between sighting batches consecutively scored for visual body condition in non-entangled North Atlantic right whales, classified as juvenile 1-2 yr (n = $10)$, juvenile $3-8 \mathrm{yr}(\mathrm{n}=28)$, adult male $(\mathrm{n}=62)$, and resting female $(n=14)$. There were no improvements observed for lactating females in this study. Timeframe comparisons for entangled whales could not be made due to inadequate sample sizes. Boxplots as in Fig. 1 


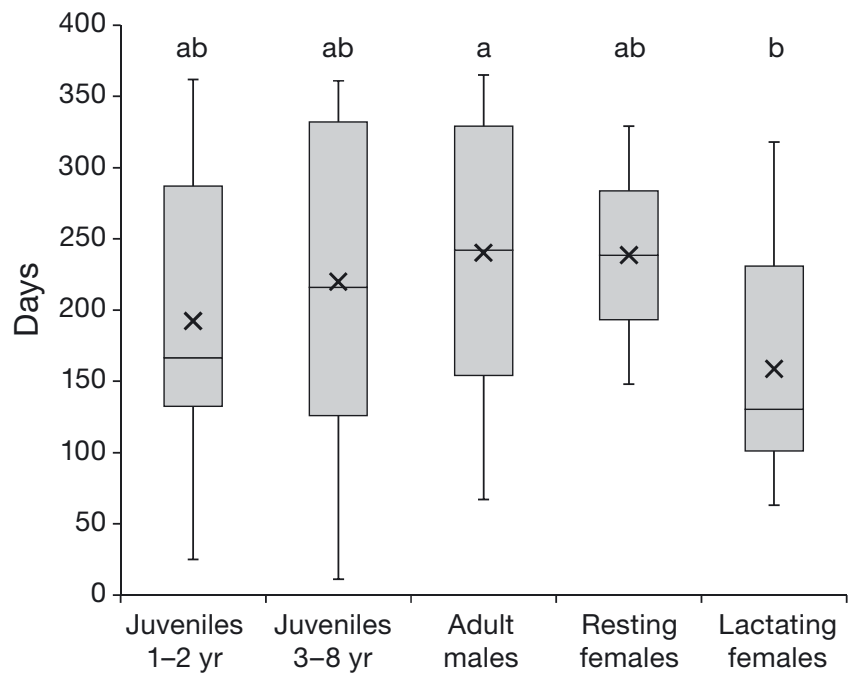

Fig. 3. Comparison of timeframes (number of days) for declining body condition between sighting batches consecutively scored for visual body condition in non-entangled North Atlantic right whales, classified as juvenile 1-2 yr (n = $32)$, juvenile $3-8 \mathrm{yr}(\mathrm{n}=37)$, adult male $(\mathrm{n}=58)$, resting female $(\mathrm{n}=2)$, and lactating female $(\mathrm{n}=28)$. Timeframe comparisons for entangled whales could not be made due to inadequate sample sizes. Boxplots as in Fig. 1

\section{Minimum body condition transition time}

Non-entangled right whales

Improvements in body condition were detected in all demographic groups except lactating females, and declines in condition were detected in all groups. Transitions to poor condition occurred in all groups except resting females, with declines recorded with a single observation for young and older juveniles, adult males, and lactating females. The time to detect body condition changes for non-entangled right whales ranged from 11 to $365 \mathrm{~d}$ and varied among age, sex, and reproductive classes (Table 2). The shortest timeframe was $11 \mathrm{~d}$ for right whale \#2212, a 6 yr old juvenile whose body condition declined from fair to poor. The shortest detected timeframe for a decline from good to fair body condition was $19 \mathrm{~d}$, observed for right whale \#3125, a 3 yr old male, and the shortest detected improvement in body condition from fair to good was $12 \mathrm{~d}$ for \#2350, an adult male. There were no changes from poor to fair condition or from poor to good condition recorded in any study group. The median timeframes across all non-entangled groups for improving and declining conditions were 197.5 and 187 d, respectively.

\section{Entangled right whales}

Fifteen body condition changes were documented in entangled whales, including 11 for severely entangled whales (Table 3 ). Of these, 9 were declines and detected in juveniles $(n=7)$ and adults $(n=2)$. Three of the 9 declines were transitions to poor condition, all of which were recorded for juveniles (Table 3). Time between body condition changes for entangled right whales ranged from 16 to $356 \mathrm{~d}$ and varied among entanglement severity levels (Table 3). The body condition change that occurred over $16 \mathrm{~d}$ occurred within a sighting batch. Right whale \#3911, a severely entangled 2 yr old female, was sighted on 30 December 2010 with a body condition score of fair. On 15 January 2011, her body condition had deteriorated to poor. She was not resighted alive; her carcass was discovered floating at sea on 1 February 2011 (Moore et al. 2012). The shortest timeframe for improving body condition (fair to good condition) for entangled whales was $47 \mathrm{~d}$, observed in right whale \#3346, a severely entangled 1 yr old, who was completely disentangled except for loose wraps of rope

Table 2. Minimum and median timeframes (number of days) between body condition changes measured visually in non-entangled North Atlantic right whales, showing number of sighting batch pairs for each change type (n) followed in parenthesis by the number of individuals contributing to these batch counts. NR: consecutively scored sighting batches for body condition were not recorded for a particular category; (-) designates condition changes with $\mathrm{n}=1$ and therefore no median value to report. Shaded rows indicate declining body condition changes. 'Poor' to 'fair' and 'poor' to 'good' transition categories are not included as those condition changes were not observed in this study

\begin{tabular}{|c|c|c|c|c|c|c|c|c|c|c|c|c|c|c|c|}
\hline \multirow{3}{*}{$\begin{array}{l}\text { Body } \\
\text { condition } \\
\text { transition }\end{array}$} & \multicolumn{6}{|c|}{ - Juveniles } & \multicolumn{3}{|c|}{ _Adult males } & \multicolumn{6}{|c|}{ Reproductive females } \\
\hline & - & $-1-2 y$ & $r$ & $\longrightarrow$ & $-3-8$ & $y \mathrm{r}-$ & & & & & _actati & $\operatorname{ing} \longrightarrow$ & 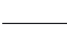 & Restin & $g$ \\
\hline & Min & Med & $\mathrm{n}$ & Min & Med & $\mathrm{n}$ & Min & Med & $\mathrm{n}$ & Min & Med & $\mathrm{n}$ & Min & Med & $\mathrm{n}$ \\
\hline Good to poor & 162 & - & 1 & NR & NR & NR & NR & NR & NR & 122 & - & 1 & NR & NR & NR \\
\hline Fair to poor & NR & NR & NR & 11 & - & 1 & 258 & - & 1 & NR & NR & NR & NR & NR & NR \\
\hline Fair to good & 51 & 148 & $10(10)$ & 39 & 246 & $28(25)$ & 12 & 179 & $62(46)$ & NR & NR & NR & 155 & 313 & $14(13)$ \\
\hline
\end{tabular}


Table 3. Minimum and median timeframes (d) between body condition changes measured visually in entangled North Atlantic right whales classified by age class (juvenile, adult and unknown) and entanglement severity (minor, moderate, and severe). See Table 2 legend for further explanation. 'Poor' to 'fair' and 'poor' to 'good' transition categories are not included as those condition changes were not observed in this study

\begin{tabular}{|c|c|c|c|c|c|c|c|c|c|c|c|c|c|c|c|c|c|c|c|}
\hline \multirow{3}{*}{$\begin{array}{l}\text { Body } \\
\text { condition } \\
\text { transition }\end{array}$} & \multirow{3}{*}{ Juv } & \multirow{3}{*}{$\overline{\text { Adult }}$} & \multicolumn{3}{|c|}{ Minor } & \multirow{3}{*}{ Juv } & \multicolumn{4}{|c|}{ - Moderate } & \multirow{2}{*}{\multicolumn{3}{|c|}{ —Juvenile - }} & \multirow{2}{*}{\multicolumn{3}{|c|}{$\begin{array}{l}\text {-Severe } \\
\text {-Adult }\end{array}$}} & \multirow{2}{*}{\multicolumn{3}{|c|}{ — Unknown- }} \\
\hline & & & 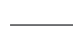 & Unk - & 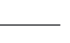 & & $\longrightarrow$ & Adult & - & Unk & & & & & & & & & \\
\hline & & & Min & Med & $\mathrm{n}$ & & Min & Med & $\mathrm{n}$ & & Min & Med & $\mathrm{n}$ & Min & Med & $\mathrm{n}$ & Min & Med & $\mathrm{n}$ \\
\hline Good to poor & NR & NR & NR & NR & NR & NR & NR & NR & NR & NR & 286 & - & 1 & NR & NR & NR & NR & NR & NR \\
\hline Fair to poor & NR & NR & NR & NR & NR & NR & NR & NR & - & NR & 16 & 95 & 2 & NR & NR & NR & NR & NR & NR \\
\hline Fair to good & NR & NR & 343 & - & 1 & NR & 342 & 349 & 2 & NR & 47 & - & 1 & NR & NR & NR & 112 & - & 1 \\
\hline
\end{tabular}

that remain around his flipper to the present day. The median timeframe times across all entangled groups for improving and declining conditions were 342 and 259 d, respectively.

\section{DISCUSSION}

This study examined the timeframe of visual body condition change for segments of the North Atlantic right whale population under varying intrinsic and extrinsic sources of energetic stress. Previous studies of right whale body condition, including ultrasonic and photogrammetric measurements, have described changes in condition in relationship to reproductive and energetic demands (Miller et al. 2011, 2012). However, no studies to date have characterized how quickly changes in body condition can be detected, or the potential impact of various sources of energetic stressors on that rate of change. The results of this study demonstrate that rapid changes in North Atlantic right whale body condition can be detected visually, with both improvements and declines in condition detected over timeframes of 12 and $11 \mathrm{~d}$, respectively. Given that the visual health assessment technique provides only a subjective semi-quantitative measure, the ability to detect body condition changes over such short timeframes is somewhat surprising.

\section{Influence of group category on body condition changes}

\section{Reproductive state}

Changes in body condition scores were significantly influenced by group category, suggesting that changes in body condition in response to different energetic pressures can be detected visually.
Significantly more incidences of declines in body condition were detected for lactating females than any other group (Table 1), while no improvements in condition were observed. Additionally, lactating females had the shortest mean time for body condition decline (158.9 d) of all groups examined, further illustrating the highly elevated energetic demands of lactation. Lactation has been described as the costliest part of the reproductive cycle for large baleen whales (Lockyer 1981), as females spend much of this period fasting while supporting the added energetic needs of a nursing calf. To support this increased energetic draw, large whales, including right whales, rely on the mobilization of lipids, including those stored in blubber, as alternate sources of energy (Lockyer et al. 1985, Miller et al. 2011). Mobilization of blubber lipids in right whales has been documented both quantitatively and qualitatively, and manifests visually by marked changes in the lateral and dorsal back profile (Pettis et al. 2004, Rolland et al. 2007b, Miller et al. 2011, 2012). Bradford et al. (2012) described similar changes in visual body condition in western gray whales Eschrichtius robustus, with lactating females in relatively worse body condition than other whales and most often observed with compromised condition. Here we have shown that the energetic drain associated with lactation in right whales is significant enough to be detected visually, and that it can be detected quite rapidly.

Although resting reproductive state in females was a significant predictor of improving body condition, these whales exhibited the longest timeframes for recovering condition compared to all groups and remained in compromised condition proportionally more often than any other non-entangled group. The depletion of energetic reserves of lactating female right whales has been previously quantified (Miller et al. 2011) and, given the significant reduction in blubber thickness in these females, full 
replenishment of these reserves may take longer than that of a whale not under such stressful energetic demands. Similarly, Bradford et al. (2012) found that, although lactating female gray whales exhibited some improvement in body condition during the feeding season, full replenishment of lost energetic reserves took longer than for other segments of the population and likely did not occur before the start of the next breeding season. Previous work on right whales suggests that a 'recovery' year between lactation and a subsequent pregnancy is necessary to restore lipid reserves to levels sufficient to support a successful full term pregnancy (Kraus et al. 2007, Miller et al. 2011). Results here further support a protracted recovery period for resting females.

\section{Age class}

Young juvenile right whales are under increased energetic stress associated with transitioning to nutritional independence as well as growth-related energetic demands (Moore et al. 2004, Miller et al. 2011, Fortune et al. 2012, 2013). Miller et al. (2011) found significant thinning of young juvenile blubber thickness immediately post-weaning, which is likely due to a combination of the elevated energetic requirements of growth, and the transition to nutritional independence and foraging inexperience. Given the thinner subcutaneous fat in young juveniles, even a short period of lipid catabolism is likely to impact the overall shape and therefore visual body condition more so than for an older whale with greater blubber thickness. Likewise, a short period of quality energetic replenishment is also likely to have a relatively more significant impact on the overall condition of these young whales. Here, improvements in body condition were less likely for juveniles 1-2 yr, but were detected over shorter timeframes compared to other group categories. Additionally, significantly more body condition scores remained at 'good' between sighting batches for adult males and juveniles 3-8 yr compared to juveniles 1-2 yr, while remaining in a compromised condition was less likely for these young whales. These data suggest that young juvenile right whales may in fact be experiencing negative body condition transitions with greater frequency than juveniles 3-8 yr and adult males; however, these depletions in condition appear to be quickly restored and many body condition transitions, particularly declines in condition, are potentially missed between sightings.

\section{Entanglement severity}

Severe entanglements hasten body condition loss in right whales, particularly for juveniles. One case of declining condition in a severely entangled whale was detected within a $16 \mathrm{~d}$ period (Table 3), one of the shortest intervals for body condition loss in this study. Additionally, all 3 declines to poor condition in severely entangled whales were recorded in juveniles, suggesting (albeit with a small sample size) that severe entanglements may disproportionately impact this class (Table 3). These results are consistent with work done by Knowlton et al. (2012), who found that more than $50 \%$ of serious entanglements involved juveniles, even though they constituted only $28.7 \%$ of the annual population composition on average. In contrast to severely entangled right whales, the body condition of whales with minor and moderate entanglements did not appear to be significantly affected by the entanglement event. There were no significant differences in the incidence of either change in condition or stable condition (remaining good or fair) detected between whales with minor and moderate entanglements and adult males. However, significantly more body condition scores remained unchanged at fair or poor for severely entangled whales compared to adult males. Finally, severe entanglement was a significant predictor of declining condition. Results of this study suggest that the impact of severe entanglements on body condition is comparable to that of the reproductive costs of lactation.

Entanglement in fixed fishing gear has a number of deleterious consequences for large whales, which increase with the severity of entanglement and directly impact the ability of the whale to maintain an energetic balance. Entanglements can cause reductions in foraging ability and efficiency, increase drag from entangling gear, and disrupt swimming performance (Lambertsen et al. 2005, Cassoff et al. 2011, van der Hoop et al. 2014), all of which increase the potential for affected whales to enter a state of negative energy balance which, if prolonged, makes recovery from such events difficult. Though the exact process and order by which right whales mobilize energy reserves is not clear, they likely follow generalized trends previously described in fasting mammals which includes mobilization of lipids followed by protein utilization (Cherel et al. 1992). The former process is lengthy and is likely in play during initial body condition loss in right whales. If conditions do not improve through either shedding of gear or disentanglement, and lost energetic reserves are not recouped (for example in a chronically entangled whale unable to feed effec- 
tively or swim efficiently), utilization of proteins and a resulting decrease in muscle mass may occur, and could result in the exaggerated concavity of the dorsal back profile seen in emaciated whales. The likelihood of this scenario would increase in a chronically and/or severely entangled juvenile whale with higher baseline energetic requirements than those of an adult whale (Fortune et al. 2013), and whose underlying blubber layer is thinner (Miller et al. 2011). This scenario may explain why proportionally more juveniles were observed declining to an emaciated state than other groups examined (Table 3). These results suggest that juvenile right whales may be more negatively affected by severe entanglements than other classes of right whales and that body condition declines due to entanglements may happen more quickly for these young whales.

The number of consecutively scored batches available for body condition evaluation increased with entanglement severity. This increase may be due to disproportionate efforts to relocate and document entanglement cases that are assessed as serious or life threatening vs. those that are considered to be minor and non-life threatening. Though this seems to be true for those whales with minor entanglements, there was no significant difference in the timeframes between scored batches for whales with moderate and severe entanglements, suggesting that these groups were scored for body condition with similar frequency (Fig. 1). Despite the possible sighting bias between types of entanglement cases, the impact of entanglement type on body condition appears to be real, as suggested by significant impact of severe entanglement injury on declining condition that was not observed in those whales with minor and moderate entanglement injuries.

\section{Considerations for interpretation}

The timeframes of body condition changes reported here probably underestimate the actual speed of such changes, since lipid mobilization and resulting body condition loss likely occur prior to visual detection. In a comparative study of body condition measurement indices, Angell (2005) estimated that a blubber thickness loss of approximately $1.34 \mathrm{~cm}$ was necessary before loss was visually detectable. Additionally, mobilization of blubber lipids is probably not uniform across the body of right whales, and lipid mobilization may occur from body regions not easily visible during visual assessment. The caudal region of fin Balaenoptera physalus, sei $B$. borealis, minke $B$. acutorostrata, and right whales has been identified as an important site for storage and mobilization of both blubber and muscular lipids (Lockyer et al. 1985, Konishi 2006, Miller et al. 2011). If primary mobilization of lipids occurs from this area and anterior lipid reserves are utilized later, the detection of visual body condition loss, which relies primarily on inspection of the dorsal body area just behind the blowholes, may indicate an already prolonged state of lipid catabolism. Lastly, blubber lipids are not the sole source of alternate energy for large whales, and additional lipid mobilization may also be from musculature and viscera (Lockyer et al. 1985, Niæss et al. 1998). It is unclear if and how the mobilization of these lipids would be reflected visually in right whales and it is very likely that significant amounts of lipids may be mobilized before changes in body shape can be detected.

The number of body condition changes detected in this study is conservative as the ability to detect changes is limited by several factors, including the variable frequency of whale sightings, the semiquantitative nature of the visual body condition assessments, and the requirement of a lateral perspective of the whale in the photographic data. Given that condition changes can happen over a matter of days and some gaps in sightings are months apart, whales may be transitioning from one condition to another and back again in between sightings. Additionally, to place changes in body condition in context, right whales need to be adequately photographed over time periods in which changes in condition can be related to biologically important events (e.g. reproduction, feeding, migration). For example, body condition of right whales in Cape Cod Bay (an important feeding habitat for this population) is difficult to assess, even from vessel platforms, because the surface feeding behavior alters the shape of the lateral profile (Pettis et al. 2004). As a result, limited body condition data are available from this important feeding habitat and limit comparisons with other habitats. Sighting heterogeneity has been previously described for right whales (Brown et al. 2001) and has implications for any monitoring and management efforts, including assessing individual and population-wide health. For example, females are often not seen in years between calving events (Brown et al. 2001); thus, their recovery after lactation is harder to document. Additionally, habitat use varies by individual, including the use of unknown habitats during various times throughout the year (Hamilton et al. 2007). Therefore, the ability to assess and score body condition is biased towards animals seen regularly in well surveyed habitats. The need for shipboard photographs restricts vi- 
sual assessments to habitats routinely monitored by vessels and to whales who utilize those habitats. Historically, most of the winter and spring high-use habitats for right whales were routinely surveyed aerially, and therefore body condition data from these areas have been limited. Recent efforts to include vesselbased efforts in some of these habitats (e.g. the southeastern US calving grounds) have increased the shipboard based data from this area. Each of these limitations has important implications for management efforts and decisions about how to best monitor population health. Changes to habitat survey frequency and design (i.e. platform type), for example, have the potential to significantly alter the quality and quantity of valuable assessment data, and therefore future management and monitoring strategies should include evaluations of these potential impacts.

The methodology used to batch right whale sightings in this study, developed first for evaluation of scarring rates in right whales and extended to the health assessment when the latter technique was developed in 2000, has been utilized in several previously published works (Knowlton et al. 2012, Schick et al. 2013, Rolland et al. 2016). Batches were organized spatially rather than temporally in the development of the methodology in order to examine changes related to habitat conditions. A 1 mo cutoff between sightings was incorporated into the batching methodology because most of the data in the Identification Database come from well surveyed habitats and as such, it was unlikely that a whale would be present and undetected for an entire month. Therefore, to take account of the fact that a whale could well have been exposed to different conditions (e.g. different habitat with different fishing or shipping pressures), if it was not seen for a month, a new batch was created. Utilizing the same batching methodology for health-related analyses allows for comparisons between the health and scarring databases and evaluation of the impacts of anthropogenic injury on health. There are limitations, however, on the ability to examine fine-scale temporal changes in visual health condition (e.g. seasonal body condition changes) using this batching methodology. For such analyses, shorter, more standardized temporal units of parameter estimates (i.e. monthly) would be required.

\section{Future research priorities}

There are several potential extensions to the work presented here. The primary objective of this study was to determine how quickly body condition changes can be detected visually for different segments of the North Atlantic right whale population. This study did not attempt to discern changes related to temporal or spatial consequences of migration, feeding, reproduction, or habitat use. Each of these factors certainly has important implications for body condition, and the Visual Health Assessment Database represents a valuable resource that could be utilized to investigate these relationships. With respect to entanglements, this study aimed to examine and compare characteristics of body change for entangled right whales with attached fixed fishing gear. However, many right whales bear only scarring evidence of entanglement events and the gear associated with these events is no longer attached (Kraus 1990, Knowlton et al. 2012). Through 2009, nearly $83 \%$ of the North Atlantic right whale population had evidence of at least one entanglement event and 59\% had evidence of more than one entanglement (Knowlton et al. 2012). There is growing concern about the sublethal impacts of entanglement events on right whales, as well as the cumulative impact of multiple entanglement events on health, reproduction, and survival (Knowlton \& Kraus 2001, Robbins et al. 2015, Rolland et al. 2016). Recently developed state-space modeling approaches that use visual health data to estimate health over time have been used to examine the impact of health on reproduction (Rolland et al. 2016), and offer opportunities to examine impacts of entanglement, including the entanglement severity, duration, and type on right whale health and survival (Schick et al. 2013).

\section{Summary and conclusion}

Results of this study provide a better understanding of the relative impact of life history events and entanglements on right whale body condition. As capital breeders, North Atlantic right whales are adapted to maintain levels of metabolic function in times of intrinsically imposed food shortages (e.g. migration, lactation) by mobilizing lipids stored in blubber and other tissues and balancing these periods with those of nutritional replenishment. Additionally, calves are buffered with reserve lipid stores to meet the increased energetic demands inherent in the transition to nutritional independence. Any added source of energetic stress, for example anthropogenic injury or changing prey abundance, will have differential effects on various segments of the population based on underlying energetic demands. This study identifies groups of animals that may be 
more susceptible to added energetic stresses than others, including young juveniles, lactating females, and severely entangled whales. Additionally, this study provides a baseline for understanding how quickly visual assessments can detect body condition changes due to different energetic stressors. Such information is particularly important to managers and researchers evaluating the potential impacts of injury and entanglements on right whales, and will allow for better informed prognoses and estimates of windows of opportunity for successful intervention for disentanglement of whales. For example, a migrating, lactating female who becomes entangled, even with a minor or moderate event, would be under multiple sources of energetic stress (lactation, migration, and added drag from entangling gear) which must be considered when making intervention determinations (e.g. gear removal, medical intervention). Finally, the ability to visually detect and monitor changes in body condition is an important tool in detecting potential population consequences of changing environmental conditions, whether due to anthropogenic activities in critical habitats, climate change, emerging diseases, or other factors.

Acknowledgements. This work was supported by the National Marine Fisheries Service under contract \#EA133F11 SE0510. We are grateful to Rob Schick for helpful comments and to the North Atlantic Right Whale Consortium and its members for their continued commitment to data sharing and a collaborative approach to conserving North Atlantic right whales. Lastly, the thoughtful comments from 3 anonymous reviewers made significant improvements to the manuscript.

\section{LITERATURE CITED}

Aguilar A, Borrell A (1990) Patterns of lipid content and stratification in the blubber of fin whales Balaenoptera physalus. J Mammal 71:544-554

Angell C (2005) Blubber thickness in Atlantic E. glacialis and E. australis. PhD dissertation, Boston University, Boston, MA

Beck GG, Smith TG, Hammill MO (1993) Evaluation of body condition in the northwest Atlantic harp seal (Phoca groenlandica). Can J Fish Aquat Sci 50:1372-1381

Best PB, Brandão A, Butterworth DS (2001) Demographic parameters of southern right whales off South Africa. J Cetacean Res Manag 2:161-169

Bradford AL, Weller DW, Punt AE, Ivashchenko YV, Burdin AM, VanBlaricom GR, Brownell RL Jr (2012) Leaner leviathans: body condition variation in a critically endangered whale population. J Mammal 93:251-266

Brown MW, Brault S, Hamilton PK, Kenney RD, Knowlton AR, Marx MK, Kraus SD (2001) Sighting heterogeneity of right whales in the western North Atlantic: 1980-1992. J Cetacean Res Manag 2:245-250

Cassoff RM, Moore KM, McLellan WA, Barco SG, Rotstein DS, Moore MJ (2011) Lethal entanglement in baleen whales. Dis Aquat Org 96:175-185

* Cherel Y, Robin JP, Heitz A, Calgari C, Le Maho Y (1992) Relationships between lipid availability and protein utilization during prolonged fasting. J Comp Physiol B 162: 305-313

Doucette GJ, Mikulski CM, King KL, Roth PB and others (2012) Endangered North Atlantic right whales (Eubalaena glacialis) experience repeated, concurrent exposure to multiple environmental neurotoxins produced by marine algae. Environ Res 112:67-76

Fortune SME, Trites AW, Perryman WL, Moore MJ, Pettis HM, Lynn MS (2012) Growth and rapid early development of North Atlantic right whales (Eubalaena glacialis). J Mammal 93:1342-1354

*Fortune SME, Trites AW, Mayo CA, Rosen DAS, Hamilton PK (2013) Energetic requirements of North Atlantic right whales and the implications for species recovery. Mar Ecol Prog Ser 478:253-272

Gerhart KL, White RG, Cameron RD, Russell DE (1996) Estimating fat content of caribou from body condition scores. J Wildl Manag 60:713-718

*Hall AJ, McConnell BJ, Barker RJ (2001) Factors affecting first-year survival in grey seals and their implications for life history strategy. J Anim Ecol 70:138-149

*Hamilton PK, Cooper LA (2010) Changes in North Atlantic right whale (Eubalaena glacialis) cow-calf association times and use of the calving ground: 1993-2005. Mar Mamm Sci 26:896-916

* Hamilton PK, Marx MK, Kraus SD (1995) Weaning in North Atlantic right whales. Mar Mamm Sci 11:386-390

Hamilton PK, Knowlton AR, Marx MK (2007) Right whales tell their own story: the photo-identification catalog. In: Kraus SD, Rolland RM (eds) The urban whale: North Atlantic right whales at the crossroads. Harvard University Press, Cambridge, MA, p 75-104

Knowlton AR, Kraus SD (2001) Mortality and serious injury of northern right whales (Eubalaena glacialis) in the western North Atlantic Ocean. J Cetacean Res Manag 2: 193-208

Knowlton AR, Hamilton PK, Marx MK, Pettis HM, Kraus SD (2012) Monitoring North Atlantic right whale Eubalaena glacialis entanglement rates: a 30 yr retrospective. Mar Ecol Prog Ser 466:293-302

Knowlton AR, Robbins J, Landry S, McKenna HA, Kraus SD, Werner T (2016) Effects of fishing rope strength on the severity of large whale entanglements. Conserv Biol 30: 318-328

Konishi K (2006) Characteristics of blubber distribution and body condition indicators for Antarctic minke whales (Balaenoptera bonaerensis). Mammal Study 31:15-22

Koopman HN, Pabst DA, McLellan WA, Dillaman RM, Read AJ (2002) Changes in blubber distribution and morphology associated with starvation in the harbor porpoise (Phocoena phocoena): evidence for regional differences in blubber structure and function. Physiol Biochem Zool 75:498-512

Kraus SD (1990) Rates and potential causes of mortality in North Atlantic right whales (Eubalaena glacialis). Mar Mamm Sci 6:278-291

Kraus SD, Rolland RM (2007) Right whales in the urban ocean. In: Kraus SD, Rolland RM (eds) The urban whale: North Atlantic right whales at the crossroads. Harvard University Press, Cambridge, MA, p 1-38

Kraus SD, Moore KE, Price CA, Crone MJ, Watkins WA, Winn HE, Prescott JH (1986) The use of photographs to 
identify individual North Atlantic right whales (Eubalaena glacialis). Rep Int Whaling Comm (Spec Issue) 10: 145-151

Kraus SD, Pace RM, Frasier TR (2007) High investment, low return: the strange case of reproduction in Eubalaena glacialis. In: Kraus SD, Rolland RM (eds) The urban whale: North Atlantic right whales at the crossroads. Harvard University Press, Cambridge, MA, p 172-199

* Lambertsen RH, Rasmussen KJ, Lancaster WC, Hintz RJ (2005) Functional morphology of the mouth of the bowhead whale and its implications for conservation. J Mammal 86:342-352

Lockyer C (1981) Growth and energy budgets of large baleen whales from the southern hemisphere. In: Gordon Clark J (ed) Mammals in the seas, Vol 3: general papers and large cetaceans. Food and Agriculture Organisation, Rome, p 379-488

Lockyer C (1986) Body fat condition in Northeast Atlantic fin whales, Balaenoptera physalus, and its relationship with reproduction and food resource. Can J Fish Aquat Sci 43: 142-147

Lockyer CH (1993) Seasonal change in body fat condition of Northeast Atlantic pilot whales, and their biological significance. Rep Int Whaling Comm (Spec Issue) 14:325-350

Lockyer CH, McConnell LC, Waters TD (1985) Body condition in terms of anatomical and biochemical assessment of body fat in North Atlantic fin and sei whales. Can J Zool 63:2328-2338

Miller CA, Reeb D, Best PB, Knowlton AR, Brown MW, Moore MJ (2011) Blubber thickness in right whales Eubalaena glacialis and Eubalaena australis related with reproduction, life history status and prey abundance. Mar Ecol Prog Ser 438:267-283

Miller CA, Best PB, Perryman WL, Baumgartner MF, Moore MJ (2012) Body shape changes associated with reproductive status, nutritive condition and growth in right whales Eubalaena glacialis and E. australis. Mar Ecol Prog Ser 459:135-156

Moore MJ, Miller CA, Morss MS, Arthur R and others (2001) Ultrasonic measurement of blubber thickness in right whales. J Cetacean Res Manag 2:301-309

Moore MJ, Knowlton A, Kraus SD, McLellan WA, Bonde RK (2004) Morphometry, gross morphology and available histopathology in North Atlantic right whale (Eubalaena glacialis) mortalities. J Cetacean Res Manag 6:199-214

Moore M, Andrews R, Austin T, Bailey J and others (2013) Rope trauma, sedation, disentanglement, and monitoringtag associated lesions in a terminally entangled North Atlantic right whale (Eubalaena glacialis). Mar Mamm Sci 29:E98-E113

Niæss A, Haug T, Nilssen EM (1998) Seasonal variation in body condition and muscular lipid contents in northeast Atlantic minke whale, Balaenoptera acutorostrata. Sarsia 83:211-218

* Nilssen KT, Haug T, Lindblom C (2001) Diet of weaned pups and seasonal variations in body condition of juvenile Barents Sea harp seals Phoca groenlandica. Mar Mamm Sci 17:926-936

Payne R, Brazier O, Dorsey EM, Perkins JS, Rowntree VJ, Titus A (1983) External features in southern right whales (Eubalaena australis) and their use in identifying individuals. In: Payne R (ed) Communication and behavior of whales. AAAs Selected Symposia Series Vol 76, Westview Press, Boulder, CO, p 371-445

Perryman WL, Lynn MS (2002) Evaluation of nutritive condi- tion and reproductive status of migrating gray whales (Eschrichtius robustus) based on analysis of photogrammetric data. J Cetacean Res Manag 4:155-164

Pettis HM, Rolland RM, Hamilton PK, Brault S, Knowlton AR, Kraus SD (2004) Visual health assessment of North Atlantic right whales (Eubalaena glacialis) using photographs. Can J Zool 82:8-19

* Pitcher KW, Calkins DG, Pendleton GW (1998) Reproductive performance of female Stellar sea lions: an energeticsbased reproductive strategy? Can J Zool 76:2075-2083

Reeves RR, Rolland R, Clapham PJ (eds) (2001) Causes of reproductive failure in the North Atlantic right whales: new avenues of research. Reference Document 01-16, Northeast Fisheries Science Center, Woods Hole, MA

Right Whale Consortium (2011) North Atlantic Right Whale Consortium 2011 Identification and Health Databases v. 08/21/2011. New England Aquarium, Boston, MA

Robbins J, Knowlton AR, Landry S (2015) Apparent survival of North Atlantic right whales after entanglement in fishing gear. Biol Conserv 191:421-427

Rolland RM, Hunt KE, Doucette GJ, Rickard LG, Wasser SK (2007a) The inner whale: hormones, biotoxins, and parasites. In: Kraus SD, Rolland RM (eds) The urban whale: North Atlantic right whales at the crossroads. Harvard University Press, Cambridge, MA, p 232-272

Rolland RM, Hamilton PK, Marx MK, Pettis HM, Angell CM, Moore MJ (2007b) External perspectives on right whale health. In: Kraus SD, Rolland RM (eds) The urban whale: North Atlantic right whales at the crossroads. Harvard University Press, Cambridge, MA, p 273-309

Rolland RM, Schick RS, Pettis HM, Knowlton AR, Hamilton PK, Clark JS, Kraus SD (2016) Health of North Atlantic right whales Eubalaena glacialis over three decades: from individual health to demographic and population health trends. Mar Ecol Prog Ser 542:265-282

* Schick RS, Kraus SD, Rolland RM, Knowlton AR and others (2013) Using hierarchical Bayes to understand movement, health, and survival in the endangered North Atlantic right whale. PLOS ONE 8:e64166

Schulte-Hostedde AI, Millar JS, Hickling GJ (2001) Evaluating body condition in small mammals. Can J Zool 79: 1021-1029

*van der Hoop JM, Moore MJ, Barco SG, Cole TV and others (2013) Assessment of management to mitigate anthropogenic effects on large whales. Conserv Biol 27:121-133

* van der Hoop J, Moore M, Fahlman A, Bocconcelli A and others (2014) Behavioral impacts of disentanglement of a right whale under sedation and the energetic cost of entanglement. Mar Mamm Sci 30:282-307

Waring GT, Josephson E, Maze-Foley K, Rosel PE (eds) (2015) US Atlantic and Gulf of Mexico marine mammal stock assessments - 2014. NOAA Tech Memo NMFS NE 231, National Marine Fisheries Service, Woods Hole, MA

Wells RS, Rhinehart HL, Hansen LJ, Sweeney JC and others (2004) Bottlenose dolphins as marine ecosystem sentinels: developing a health monitoring system. EcoHealth 1:246-254

*Williams R, Vikingsson WR, Gislason A, Lockyer C, New L, Thomas L, Hammond PS (2013) Evidence for densitydependent changes in body condition and pregnancy rate of North Atlantic fin whales over four decades of varying environmental conditions. ICES J Mar Sci 70: 1273-1280

* Young RA (1976) Fat, energy and mammalian survival. Am Zool 16:699-710 